\title{
Combinación de carcinomas de riñón y próstata, con metástasis del primero a parótida y pulmón
}

\author{
Combination of renal cell carcinoma and \\ adenocarcinoma of the prostate, with metastases \\ of the former to the parotid gland and the lung
}

\author{
Gonzalo Mejía・Medellín
}

\section{Resumen}

Se presenta el caso de un paciente con carcinoma renal izquierdo a quien se le realizó nefrectomía radical e hizo metástasis tardías primero a parótida derecha (a los cuatro años), manejada con parotidectomía y vaciamiento radical del cuello, y un año más tarde a pulmón derecho, por la cual se le practicó lobectomía superior. Un año después de la nefrectomía había tenido adenocarcinoma de próstata tratado con prostatectomía radical. Se discuten tanto el caso, como la información actual acerca de la combinación de estas neoplasias en un paciente (Acta Med Colomb 2009; 35: 26-30).

Palabras clave: carcinoma de células renales, neoplasia de parótida, neoplasia metastásica.

\begin{abstract}
Abastract
The case is reported of a patient with renal cell carcinoma who underwent radical nephrectomy. Four years later, metastases were found in the right parotid gland. Surgical excision of the parotid and radical neck dissection were then performed. One year later, metastases were found in the right lung, which prompted surgical ablation of the upper lobe. One year after the nephrectomy, the patient presented with adenocarcinoma of the prostate, which required radical prostatectomy. A discussion of the case and of recent information about the combination of these neoplastic diseases is carried out (Acta Med Colomb 2009; 35: 26-30).
\end{abstract}

Keywords: renal cell carcinoma, parotid neoplasms, neoplasm metastasis.
Dr. Gonzalo Mejía: Médico Internista, Nefrólogo, Director Científico Clínica Las Américas, Medellín.

No hubo financiación para esta publicación.

No declaro ningún conflicto de interés.

Correspondencia: Gonzalo Mejía, M.D. Torre Médica Las Américas. Diag. 75 B No. 2A - 80 Cons 720. Tel (4) $3421010 \mathrm{X}$ 1033 - (4) 345 9265. Fax (4) 347 1696. Cel 311617 8786, Medellín

E-mail: fmejia22@une.net.co

Recibido: 05/VIII/09 Aceptado: 09/XII/09

\section{Caso clínico}

Hombre, 61 años. Fecha de primera consulta noviembre 7 de 2003. Fue remitido a consulta de nefrología porque le habían encontrado creatinina anormal en chequeo rutinario anual realizado en su programa de seguimiento de hipertensión arterial. No manifestaba ningún síntoma excepto disminución del calibre del chorro al orinar. No había tenido hematuria ni infecciones urinarias.

Antecedentes: hipertensión arterial de 15 años de evolución, hernia de disco L4-L5 estable, hipotiroidismo controlado, glaucoma bilateral, tratado quirúrgicamente, estable. Hace ejercicio regularmente. No fuma. Poco licor. Padre murió de infarto miocárdico (era hipertenso), madre de enfisema (tabaquismo). Un hermano con temblor fino. No antecedentes de cáncer en la familia.
EF: Buenas condiciones, PA 210/112, pulso 80/min, peso $73.5 \mathrm{k}$, fondo de ojo: cruces cruces arteriovenosos, orificios de iridotomía en parte superior de córneas, no pálido, cuello bien, pulmones bien, corazón bien, abdomen bien sin masas ni megalias, leve reducción de pulsos distales de miembros inferiores, temblor fino distal al escribir. Tacto rectal, hecho por urólogo una semana antes fue reportado como "bien".

Con base en la clínica y los exámenes de laboratorio, se hicieron los siguientes diagnósticos: insuficiencia renal crónica estadío 3 probablemente secundaria a hipertensión arterial, hipertensión arterial crónica no controlada, temblor familiar, antecedente de hernia de disco L4 - L5, hipotiroidismo en tratamiento, prostatismo leve, antecedente de glaucoma bilateral, enfermedad arterial oclusiva de miembros inferiores leve y dislipidemia tratada. 


\begin{tabular}{|c|c|c|c|c|c|c|c|c|c|c|c|c|c|c|c|c|}
\hline & \multicolumn{16}{|c|}{ FECHAS } \\
\hline & & $\begin{array}{c}\text { Oct } \\
22 / 03\end{array}$ & $\begin{array}{c}\text { Nov } \\
18 / 03\end{array}$ & $\begin{array}{l}\text { Feb } \\
4 / 04\end{array}$ & $\begin{array}{l}\text { Mar } \\
8 / 04\end{array}$ & $\begin{array}{l}\text { Nov } \\
18 / 04\end{array}$ & $\begin{array}{c}\text { Ago } \\
16 / 05\end{array}$ & $\begin{array}{c}\text { Ago } \\
22 / 06\end{array}$ & $\begin{array}{l}\text { Dic } \\
14 / 06\end{array}$ & $\begin{array}{l}\text { May } \\
31 / 07\end{array}$ & $\begin{array}{l}\text { Nov } \\
\text { 1/07 }\end{array}$ & $\begin{array}{l}\text { Mar } \\
\text { 3/08 }\end{array}$ & $\begin{array}{c}\text { Jul } \\
3 / 08\end{array}$ & $\begin{array}{c}\text { Oct } \\
23 / 08\end{array}$ & $\begin{array}{c}\text { Mar } \\
5 / 09\end{array}$ & $\begin{array}{c}\text { May } \\
26 / 09\end{array}$ \\
\hline $\begin{array}{l}\text { MOMENTO } \\
\text { CLÍNICO } \longrightarrow\end{array}$ & \multirow[b]{2}{*}{ 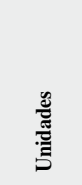 } & \multirow{2}{*}{ 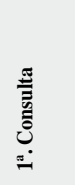 } & \multirow{2}{*}{ 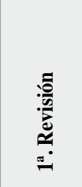 } & \multirow{2}{*}{ 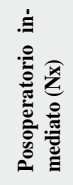 } & \multirow[b]{2}{*}{ 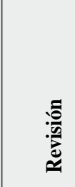 } & \multirow[b]{2}{*}{ 言 } & \multirow[b]{2}{*}{$\begin{array}{l}\frac{5}{2} \\
\frac{2}{2} \\
\simeq\end{array}$} & \multirow[b]{2}{*}{ 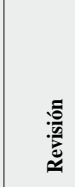 } & \multirow{2}{*}{ 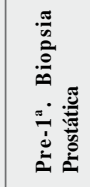 } & \multirow{2}{*}{ 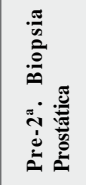 } & \multirow{2}{*}{ 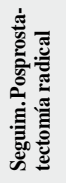 } & \multirow{2}{*}{ 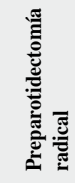 } & \multirow{2}{*}{ 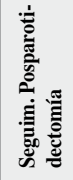 } & \multirow[b]{2}{*}{ ๕: } & \multirow{2}{*}{ 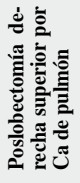 } & \multirow[b]{2}{*}{ 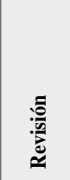 } \\
\hline PRUEBA & & & & & & & & & & & & & & & & \\
\hline Hemoglobina & $\mathrm{g} / \mathrm{L}$ & 18.6 & - & 16.3 & - & 16.9 & 17.2 & 17.9 & - & 16.5 & 16.8 & - & 16.7 & 16.6 & 14.9 & 14.4 \\
\hline Hematocrito & $\%$ & 55 & - & 46 & - & 48 & 49 & 51 & - & 46 & 47 & - & 49 & 50 & 45 & 43 \\
\hline BUN & $\mathrm{mg} / \mathrm{dL}$ & - & & 21 & 29 & 21.9 & 20.6 & 19 & - & 25 & 21 & 29 & 24 & 23 & 26 & 31 \\
\hline Creatinina & $\mathrm{mg} / \mathrm{dL}$ & $\begin{array}{c}1.35 \\
(0.3-1.2)\end{array}$ & $\begin{array}{c}1.44 \\
(0.3-1.2)\end{array}$ & 2.38 & 1.75 & 1.87 & 1.82 & 1.81 & 1.84 & $\begin{array}{c}1.81 \\
(0.8-1.3)\end{array}$ & 1.62 & 1.75 & 1.86 & $\begin{array}{c}1,78 \\
(0.8-1.3)\end{array}$ & $\begin{array}{c}1.67 \\
(0.8-1.3)\end{array}$ & $\begin{array}{c}1.78 \\
(0.8-1.3)\end{array}$ \\
\hline Colesterol & $\mathrm{mg} / \mathrm{dL}$ & 224 & - & - & 224 & 159 & 184 & - & 217 & 219 & 185 & 224 & 178 & - & 199 & \\
\hline Triglicéridos & $\mathrm{mg} / \mathrm{dL}$ & 181 & - & - & 145 & & 178 & - & 222 & 188 & 192 & 145 & 216 & - & 201 & \\
\hline TSH & U.I. & 10.13 & - & - & - & 6.56 & 3.82 & 3.32 & & & 3.26 & - & & - & 3.09 & \\
\hline PSA & & 2.29 & - & - & - & - & 3.35 & 4.68 & 4.8 & 6.3 & 0.003 & - & 0.071 & 0.072 & 0.132 & 4.4 \\
\hline Ácido úrico & $\mathrm{mg} / \mathrm{dL}$ & 4.4 & - & - & - & - & 5.5 & - & - & - & - & - & - & - & 5.12 & 9.5 \\
\hline Calcio & $\mathrm{mg} / \mathrm{dL}$ & & 9.2 & & - & - & 9.7 & 8.9 & - & 9.2 & & - & & 9.03 & 9.3 & \\
\hline Depuración de creatinina & $\mathrm{ml} / \mathrm{min}$ & - & 73 & - & - & - & 50.2 & - & - & 73 & - & - & - & - & - & - \\
\hline Proteinuria / 24h & g/día & - & 0.23 & - & - & - & 0.162 & - & - & 0.23 & - & - & - & - & - & - \\
\hline Proteinuria ocasional & $\mathrm{mg} / \mathrm{dL}$ & - & - & - & Negat. & - & - & Negat. & - & - & - & Negat. & Negat. & Negat. & Negat. & Negat. \\
\hline
\end{tabular}

Nota: Cifras entre paréntesis representan valores de referencia.

Evolución: se le ordenaron exámenes de laboratorio (Tabla 1) y ecografía abdominal y se continuó la terapia que traía (captopril $50 \mathrm{mg} \mathrm{1/dL}$, levotiroxina $50 \mathrm{mcg} \mathrm{1/dL}$, ciprofibrato $100 \mathrm{mg} 1 / \mathrm{dL}$ ) mientras se recibían los resultados.

La ecografía (noviembre 18, 2003) mostró lesión compleja en 1/3 superior de cara externa del riñón izquierdo de $5.5 \mathrm{~cm}$ de diámetro, sugestiva de hipernefroma necrótico. Debido a la falla renal, se le hizo resonancia magnética abdominal (diciembre 3, 2003) que reveló lesión neoplásica con componente sólido hipercaptante periférico y componente quístico necrótico central con posible ganglio paraaórtico (Figura 1). Se le incrementó la dosis de captopril a $50 \mathrm{mg}$ cada 8 horas. Se le propuso nefrectomía $(\mathrm{Nx})$ radical izquierda, que el paciente aceptó después de explicarle riesgos y beneficios.

La Nx se realizó en enero 29 de 2004, sin complicaciones. El reporte anatomopatológico informó que había carcinoma de células claras (hipernefroma), pero sin caracterización adicional del tipo nuclear, ni clasificación de Fuhrman. Desde antes de la cirugía tenía creatinina un poco elevada; después de ésta, aumentó un poco más y se estabilizó.

A partir de agosto 2006 empezó a presentar incremento en los valores del antígeno específico de próstata (PSA). En febrero de 2007 se le practicó biopsia de próstata que fue normal. Como los niveles de PSA siguieron ascendiendo, se le repitió en julio 2007 y se encontró adenocarcinoma de lóbulo izquierdo. En julio 23 se practicó prostatectomía radical y el resultado anatomopatológico fue adenocarcinoma bilateral tipo acinar, grado $3-4$ de Gleason que comprometía $10 \%$ de la glándula, con invasión perineural. No recibió otros tratamientos para esta neoplasia.

Poco después notó masa en lado derecho de cuello. Esto condujo a que en marzo de 2008 se le hiciera biopsia por aspiración con aguja fina (BACAF) que no mostró malignidad. No obstante, sobre bases clínicas se decidió practicar parotidectomía derecha con vaciamiento radical del cuello. El resultado de la anatomía patológica fue adenocarcinoma de células claras (Figura 2); los ganglios linfáticos no mostraron compromiso neoplásico. Después de la resección de la masa recibió radioterapia en el cuello derecho.

En la revisión de octubre de 2008 refería incontinencia e impotencia, alopecia, disgeusia y dermatitis por radiación de cuello derecho. La función renal estaba estable. En los controles de enero de 2009, se le hicieron exámenes de control los que llevaron a diagnosticar metástasis del cáncer a pulmón derecho. A raíz de este hallazgo, se le realizó lobectomía superior y la patología reveló compromiso por adenocarcinoma de células claras en el segmento pulmonar, en las metástasis y en los ganglios resecados. Inició quimioterapia con ciclos de interleukina - 2. Para marzo de 2009, continuaba estable tanto por clínica como por laboratorio. 

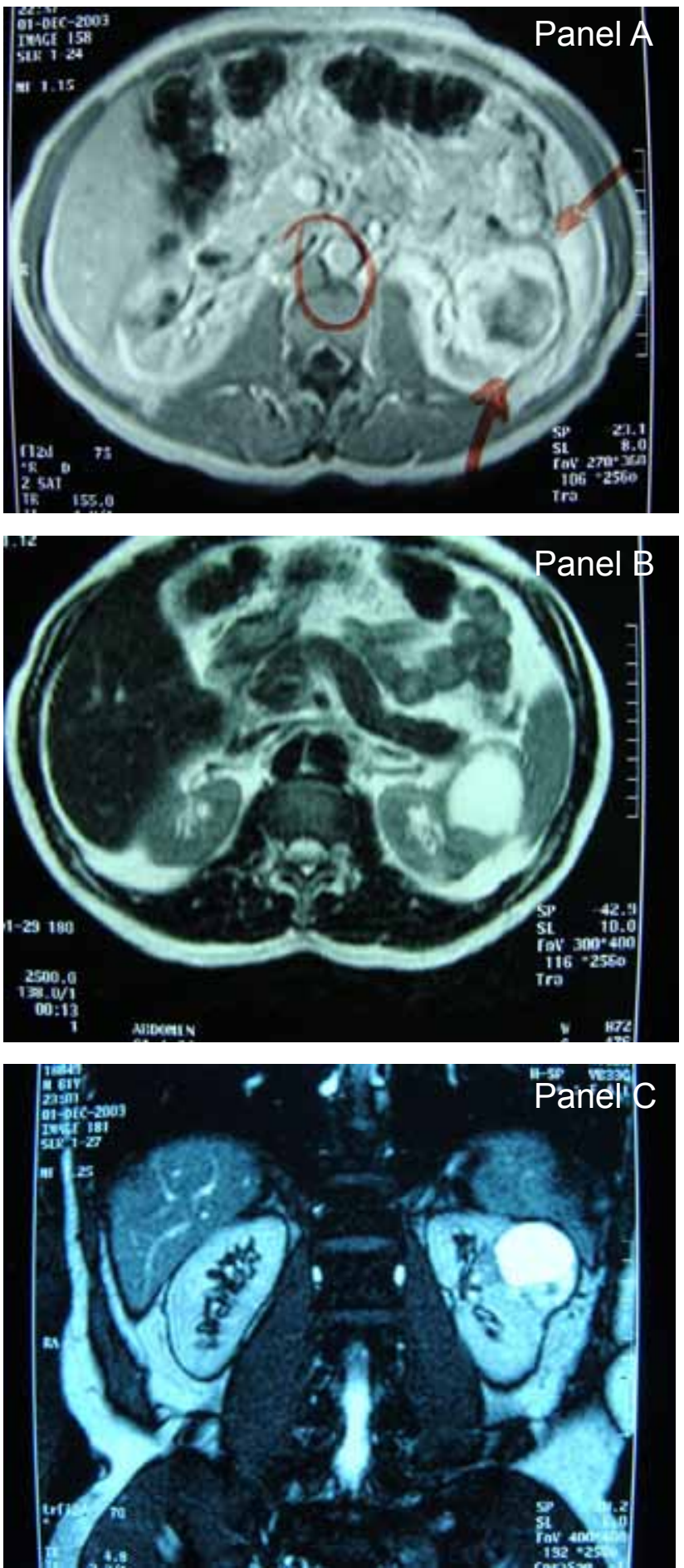

Figura 1. Cortes de la resonancia magnética abdominal (diciembre 3, 2003) que reveló lesión neoplásica con componente sólido hipercaptante periférico y componente quístico necrótico central con posible ganglio paraaórtico. (Panel A: Sin contraste. Panel B: Con contraste. Panel C: Corte anteroposterior).

En su última revisión en mayo 26, 2009 se encontraba clínicamente bien, en quimioterapia con ciclos periódicos de interleukina - 2 y con evidencia de estabilización del proceso neoplásico, así como de sus exámenes de laboratorio.

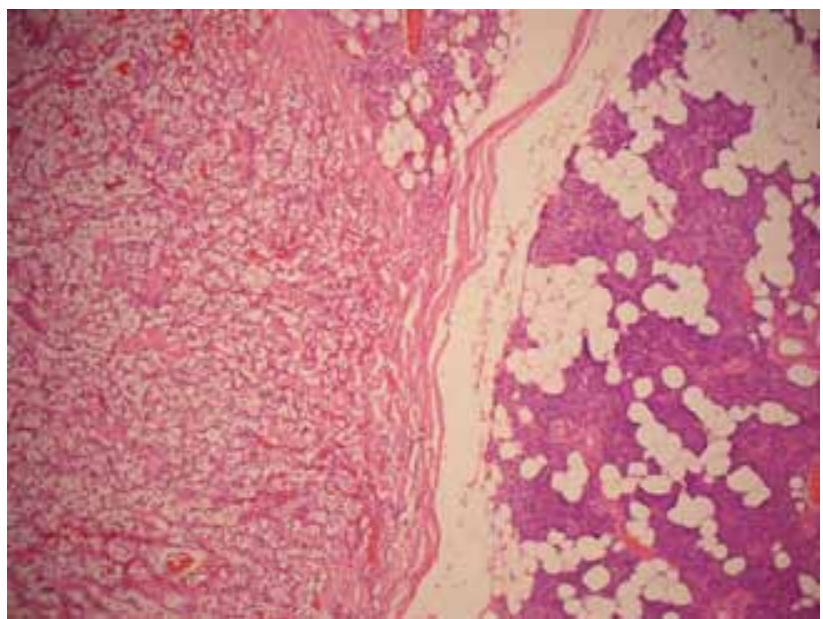

Figura 2. Microfotografía de la pieza quirúrgica de la parótida del paciente que muestra la metástasis del carcinoma de células claras de riñón. Se observa la interfase entre el tumor (lado izquierdo) y la glándula parótida normal. (Coloración de H. E. 100X).

\section{Discusión}

Se reporta el caso de un paciente con neoplasia múltiple que incluye carcinomas de riñón, próstata y metástasis tardías de la neoplasia del riñón a parótida y pulmón (4 y 5 años después respectivamente). El objetivo de comunicar este caso es resaltar la posibilidad de combinación asincrónica de estas neoplasias y de aparición de las metástasis mencionadas en sitios poco comunes como la parótida, varios años después de haber sido resecado el tumor renal original. Además, no hay publicaciones sobre este tópico en la literatura médica colombiana.

Hasta hace dos décadas, el carcinoma de células renales (CCR) se diagnosticaba casi siempre como resultado de hallazgos clínicos sospechosos como hematuria, dolor lumbar, masa a la palpación bimanual del abdomen o aparición de metástasis. Con la utilización cada vez mayor de imágenes diagnósticas (ecografía, tomografía o resonancia) para evaluar síntomas abdominales, la frecuencia con la cual se encuentra CCR asintomático en forma incidental, como en el caso que se reporta, ha aumentado hasta representar la mayoría (1). Un estudio muestra que el hallazgo incidental ha pasado de $25 \%$ en el periodo $1970-1995$ a $54.4 \%$ en el de 1996-2005 (2).

El diagnóstico temprano ha permitido mejorar el pronóstico y lograr la curación, con cirugía como único tratamiento (3). En un reporte de 209 casos de pacientes intervenidos por CCR no metastático, se encontró que 39 de ellos (18.7\%) presentaron metástasis múltiples; la gran mayoría de estos fue a pulmón seguido de hueso, hígado y cerebro (3). En este artículo no se menciona la parótida. El diagnóstico histológico de las metástasis fue de carcinoma de células claras (CCC) en 38 de los 39 casos (97\%).

Los carcinomas de las glándulas salivares representan el $3 \%$ de todos los tumores, su incidencia es de 2 por 100.000 en EE.UU. (rango 1.6-2.5); el 80\% son de la parótida y de éstos, $20 \%$ a $40 \%$ son malignos $(4,5)$. De los tumores 
salivares, $3 \%$ a $8.1 \%$ son metastásicos y de las metástasis, $83 \%$ se originan en tumores de tejidos blandos de cabeza y cuello. Las de órganos infraclaviculares son principalmente de pulmón y con menor frecuencia de mama, riñón o tracto gastrointestinal $(4,5)$. El porcentaje que proviene de riñón se ha estimado en $3.7 \%$ (6).

Un artículo reciente reporta que de 48 pacientes sometidos a parotidectomía por tumor, en 12 (25\%) se diagnosticó metástasis de un tumor primario; de éstos, 9 fueron de piel (carcinoma epidermoide 8, melanoma 1), 2 fueron linfomas y 1 fue de CCC de riñón (7). En un 40\% de los casos, las metástasis parotídeas son la primera manifestación de malignidad.

El CCR representa el $2 \%$ a $3 \%$ de todas las neoplasias y su incidencia es de 8.9 por 100.000 en EE.UU. Predomina en hombres, en mayores de 60 años y en afroamericanos. La gran mayoría son esporádicos y sólo $4 \%$ son familiares (1). La incidencia ha venido aumentando en las últimas décadas debido a su hallazgo incidental, lo que también ha mejorado las tasas de supervivencia.

El hallazgo de adenocarcinoma de células claras en el estudio anatomopatológico de riñón, parótida y pulmón permite sugerir desde el punto de vista epidemiológico que son el mismo tumor, pero la prueba no podría tenerse sin hacer estudios de inmunohistoquímica (tinciones para Vimentina, CD10 y PNRA, y pruebas para evaluar la expresión de moléculas de adhesión celular [cell-adhesion molecules-CAMs], cadherina, integrina, así como varios otros biomarcadores) $(5,8)$ que no son de rutina en la práctica clínica. Por otra parte, el CCR expresa también antígenos que pueden servir para su caracterización (PRAME, RAGE-1, MUC-1, gp47 y CA-9). El CA-9 (o MN-9), es el de mayor especificidad, es reconocido por el anticuerpo monoclonal G250 y se expresa en $70 \%$ - 90\% de los CCC (1). Estas observaciones contrastan con la pobre respuesta a la inmunoterapia que se ha obtenido.

El tiempo transcurrido entre la Nx y la aparición de las metástasis en parótida oscila entre 2 y 10 años, pareciendo que a medida que se alejan los dos eventos, disminuyen las probabilidades de que ocurran las segundas $(9$ - 11). Más aún, en el único caso reportado de metástasis a parótida a los 10 años de la Nx, un año después de la parotidectomía la paciente desarrolló CCC en el riñón contralateral y debió ser sometida a Nx radical, quedando anéfrica y en tratamiento con hemodiálisis crónica. El compromiso bilateral del CCR, sincrónico o asincrónico, ocurre en $2 \%$ a $4 \%$ de los pacientes con esta neoplasia (1).

En un estudio de CCC renales asociados a masa parotídea se reportan los 25 casos de la literatura en inglés (hasta 2002). En 14 de ellos (56\%), la metástasis parotídea fue la manifestación inicial del cáncer (12).

Aunque la progresión de la masa renal está bien definida, el desarrollo de metástasis a distancia es poco común y se encuentra pobremente documentado $(13,14)$. El pronóstico empeora cuando están presentes las siguientes situaciones: el diámetro de la masa es $>5 \mathrm{~cm}$; hay extensión por fuera de la fascia, a órganos contiguos y venosa ascendente; se encuentran metástasis sincrónicas a vísceras (diferentes de pulmón) y a ganglios retroperitoneales; el estadío, el grado nuclear y el subtipo histológico son más avanzados; el intervalo libre de metástasis es menor, hay presencia de obesidad, hay deterioro del estado general al momento del diagnóstico, la presentación clínica incluye signos y síntomas propios del tumor o paraneoplásicos, y hay disminución de peso $>10 \%$ (1).

Un metaanálisis reciente sobre masas renales (15) reunió 234 casos que fueron seguidos activamente; el diámetro mayor promedio de la masa al momento del diagnóstico fue de $2.6 \mathrm{~cm}$ y $86 \%$ fueron $<4 \mathrm{~cm}$. Al final del seguimiento que fue de 34 meses en promedio, sólo en tres casos (1\%) se desarrollaron metástasis. De otro lado, $25 \%$ de los pacientes tiene enfermedad local avanzada o diseminada al momento del diagnóstico (16).

Sobre estas bases se ha propuesto que la conducta a seguir con masas pequeñas $(<4 \mathrm{~cm})$ es vigilancia activa (13) con estudios imaginológicos cada seis meses, pues aunque $34 \%$ de las masas progresa, ninguna hizo metástasis.

La ocurrencia de carcinomas renal y de próstata en un mismo paciente se ha reportado ocasionalmente pero sin establecerse asociación entre ellos. En un estudio se evalúa la influencia del tipo histológico en la posible asociación con una segunda neoplasia primaria (17); en dicho estudio se hizo seguimiento a 763 pacientes que fueron nefrectomizados por CCR entre 1989 y 1999 y se determinó la incidencia de segundas neoplasias antecedentes, sincrónicas o subsecuentes al tumor renal. Se encontraron 209 segundas neoplasias $(27.4 \%)$, siendo las más frecuentes, las de próstata, mama, colon, vejiga y el linfoma no Hodgkin. De las $209,44.5 \%$ fueron antecedentes, $39.2 \%$ sincrónicas y $16.2 \%$ subsecuentes. Otros trabajos han reportado que esta asociación se da principalmente con el carcinoma renal de tipo papilar y que es más frecuente entre cánceres de vejiga y próstata. Los autores concluyen que en los pacientes con carcinoma papilar hay un riesgo incrementado de desarrollar cánceres de vejiga y próstata, pero no en los que presentan $\mathrm{CCC}$, como es el caso de paciente que se describe.

En conclusión, el reporte de este caso busca alertar sobre la ocurrencia rara pero posible de metástasis del CCC de riñón a sitios raros como la parótida y que una masa parotídea puede ser la primera manifestación de un cáncer renal. La metástasis pulmonar es signo de enfermedad neoplásica progresiva. No parece existir una relación causal o fisiopatológica entre el CCR y el adenocarcinoma de próstata y su concurrencia asincrónica en casos como el del paciente descrito, puede considerarse producto del azar.

\section{Agradecimientos}

A la Dra. Carolina Echeverry, médica patóloga, Directora del Laboratorio de Patología de Clínica Las Américas por las fotos de la histología. A la Dra. Angela Builes, médica coordinadora de estudios clínicos de la Dirección Científica de Clínica Las Américas por la revisión del manuscrito. 


\section{Referencias}

1. Campbell SC, Novick AC, Bukowski RM. Tumores renales. En: CampbellWalsh. Urología. 9a ed; Buenos Aires; Panamericana; 2007.p.1567-637.

2. Bulnes Vásquez V, Alvarez Mugica M, Fernández Gómez JM, Nava Tomás E, Jalón Monzón A, Leilán Martínez A. Características clínico-patológicas del carcinoma de células renales detectado incidentalmente mediante estudios radiológicos. Acta Urol Esp 2008; 32: 976-984.

3. Sivaramakrishna B, Gupta Narmada P, Wadhwa P. Pattern of metastases in renal cell carcinoma: A single institution study. Indian J Cancer 2005; 42: 173 177.

4. Luna MA. Pathology of tumors or the salivary glands. En: Thawley SE, Panje WR, Batsakis JG, Lindberg RD, eds. Comprehensive management of head and neck tumors, 2a ed; Filadelfia; WB Saunders; 1999.p.1105-146.

5. Mrena R, Leivo I, Passador-Santos F, Hagström J, Mäkitie AA. Histopathological findings in parotid gland metastases from renal cell carcinoma. Eur Arch Oto-Rhino-Laringol 2008; 265: 1005-9.

6. Lacosta JL, Zabaleta M, Infante JC. Surgical pathology of parotid gland tumors. Acta Otorrinolaringol Esp 1997; 48: 653-7.

7. Pomar Blanco P, Martín Villares C, San Román Carbajo J, Tapia Risueño M, Fernández Pello M. Metástasis en glándula parótida. Acta Otorrinolaringol Esp 2006; 57: 47-50.

8. Andreadis D, Nomikos A, Barbatis C. Metastatic renal clear cell carcinoma in the parotid gland: a study of immunohistochemical profile and cell-adhesion molecules expresión in two cases. Pathol Oncol Res 2007; 13: 161-5.
9. Spreafico R, Nicoletti G, Ferrario F, Scanziani R, Grasso M. Parotid gland metastasis from renal cell carcinoma: a case report and review of the literature. Acta Otorhynolaringol Ital 2008; 28: 266-8.

10. Owens RM, Friedman CD, Becker SP. Renal cell carcinoma with metastasis to the parotid gland: case reports and review of the literature. Head Neck 1989; 11: 174-8.

11. Gögüs C, Kilic Ö, Tulunay Ö, Tulunay Ö, Bedük Y. Solitary metastasis of renal cell carcinoma to the parotid gland 10 years after radical nephrectomy. Internat J Urol 2004; 11: 894-896.

12. Park YW, Hlivko TJ. Parotid gland metastasis from renal cell carcinoma. Laryngoscope 2002; 112: 453-6.

13. Jewett MAS, Zuniga A. Renal tumor natural history: the rationale and role for active surveillance. Urol Clin N Am 2008; 35: 627-34

14. Rini BI, Campbell C, Escudier B. Renal cell carcinoma. Lancet 2009; 373: 1119-32.

15. Chawla SN, Crispen PL, Hanlon AL. The natural history of observed enhancing renal masses: meta-analysis and review of the world literature. J Urol 2006; 175: 738-45.

16. Lane BR, Kattan MW. Prognostic models and algorithms in renal cell carcinoma. Urol Clin N Am 2008; 35: 613-25.

17. Rabbani F, Reuter VE, Katz J, Russo P. Second primary malignancies associated with renal cell carcinoma: influence of histologic type. Urology 2000; 56: 399-403. 